\title{
CORRIGENDUM
}

\section{ILM Volume 59 Issue 6 Cover and Front matter-CORRIGENDUM}

In the original published cover, the TOC entry for Marie Joseph Ayissi was incorrect. This has since been corrected in the original published cover online.

\section{REFERENCE}

1. ILM volume 59 Issue 6 Cover and Front matter. International Legal Materials, 59(6), i. doi: https://doi.org/10. 1017/ilm.2020.61. 